\title{
A randomized experiment of the split benefit health insurance reform to reduce high-cost, low-value consumption
}

This article was published in the following Dove Press journal:

Innovation and Entrepreneurship in Health

5 September 2014

Number of times this article has been viewed

\section{Christopher T Robertson' \\ David V Yokum² \\ Nimish Sheth ${ }^{3}$ \\ Keith A Joiner ${ }^{4}$}

'James E Rogers College of Law, The University of Arizona, ${ }^{2}$ Department of Psychology, The University of Arizona, Tucson, AZ, ${ }^{3}$ University of Southern California Gould School of Law, Los Angeles, CA, ${ }^{4}$ College of Medicine and Eller College of Management, The University of Arizona, Tucson, AZ, USA

\section{Video abstract}

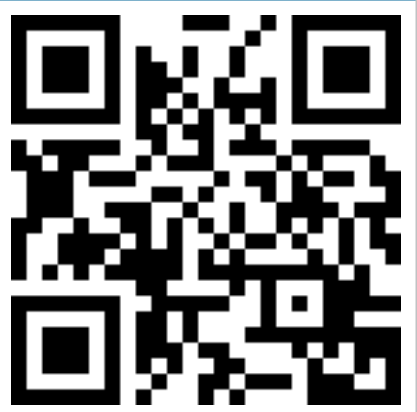

Point your SmartPhone at the code above. If you have a $Q R$ code reader the video abstract will appear. Or use: http://dvpr.es/ljinBSr

Correspondence: Keith A Joiner Center for Management Innovations in Health Care, Eller College of Management, McClelland Hall, Room 4I I, I I 30 Helen Street, Tucson, AZ, 857I8, USA

Tel +I 5206264655

Email kjoiner@email.arizona.edu

Abstract: Traditional cost sharing for health care is stymied by limited patient wealth. The "split benefit" is a new way to reduce consumption of high-cost, low-value treatments for which the risk/benefit ratio is uncertain. When a physician prescribes a costly unproven procedure, the insurer could pay a portion of the benefit directly to the patient, creating a decision opportunity for the patient. The insurer saves the remainder, unless the patient consumes. In this paper, a vignette-based randomized controlled experiment with 1,800 respondents sought to test the potential efficacy of the split benefit. The intervention reduced the odds of consumption by about half. It did so regardless of scenario (cancer or cardiac stent), type of split (rebate, prepay, or health savings account), or amount of split (US\$5,000 or US\$15,000). Respondents viewed the insurer that paid a split as behaving fairly, as it preserved access and choice. Three-quarters of respondents supported such use in Medicare, which did not depend on political party affiliation. The reform is promising for further testing since it has the potential to decrease spending on low-value interventions, and thereby increase the value of the health care dollar.

Keywords: insurance, payment, reform, incentive, benefit

\section{Introduction and background}

The problem of costly unproven health care

A primary goal of health insurance reformers is to move consumption away from the high-cost, low-value health care, which is a major driver of the growth of health insurance costs. Some "expensive treatments, such as stents for cardiovascular disease, are high value for some patients but poor value for others". ${ }^{1}$ There is also "a large and expanding set of treatments, such as proton beam therapy or robotic surgery, that contribute to rapid increases in spending despite questionable health benefits". ${ }^{1}$ Although "estimates vary, some experts believe that less than half of all medical care is based on or supported by adequate evidence about its effectiveness". ${ }^{2}$ In some sectors of health care, "off-label" prescriptions - those that are being used for purposes where the Food and Drug Administration has not reviewed efficacy - account for half of all prescriptions. ${ }^{3}$

Broad-based initiatives, such as Choosing Wisely, ${ }^{4}$ Clinical Evidence, ${ }^{5}$ Less is More, ${ }^{6}$ National Institute for Health and Clinical Excellence, ${ }^{7}$ and recent reviews, ${ }^{8}$ focus on identifying which procedures provide minimal or no benefit. In the US, no single solution has been proposed to drive adoption of these recommendations by the medical community. There are political, legal, and market limits that prevent insurers and physicians from simply rationing care, at least in the US. While a physician-based approach to cost containment for low-value, low-cost interventions must be a central 
component in bending the cost curve, voluntary adoption of the recommendations by physicians, based on guidance from expert panels, suffers from slow adoption and may be contrary to professional norms and incentives. ${ }^{1}$

\section{The limits of traditional cost sharing}

Cost sharing is the most commonly discussed approach to this issue of moral hazard, where patients consume low-value care without regard for cost. Some public and private insurers are changing cost sharing policies by increasing co-pays, co-insurance, and deductibles. These "consumer-directed care" policies are designed to cause patients to weigh the benefits of such procedures against a portion of the costs, and they work to reduce consumption without harming health, in some situations. ${ }^{9,10}$

Cost sharing does not, however, work for highly expensive treatments, far beyond the scale of patient wealth. Instead, insurers provide annual limits on their beneficiaries' out-of-pocket obligations. Most workers (59\%) have cost sharing obligations capped at some amount less than US\$3,000 per year. "'Once consumers reach the limits of the deductible, they have little reason to limit their consumption of health care or to pay attention to its price." ${ }^{12}$

While an obvious solution is to simply raise the limits, in a world of limited patient wealth, such increases begin to defeat the purpose of insurance (pooling risk and guaranteeing access to care). ${ }^{13}$ Consequently, some patients refuse high-value care, and others who stretch to buy care are forced to declare bankruptcy. ${ }^{9,14-17}$

\section{The split benefit model}

This article tests a novel solution in health insurance policy design, called a "split benefit", focusing on high-cost interventions for which the value is uncertain. Currently, insurance is provided as an "in-kind" benefit, which is paid directly to the provider; this creates a sunk cost, thereby biasing decisions toward consumption. In the split benefit model, the insurer can split the benefit between the beneficiary and the provider. ${ }^{18}$ The insurer pays the provider only if the patient consumes.

For example, for an expensive (say, US\$50,000) procedure that the physician prescribes and the insurer must cover, the insurer will pay to the patient a fraction of the charge for the treatment (say, US\$5,000). Then, the patient will have the option of using that US\$5,000 for the treatment, with the insurer matching by paying the US\$45,000 to the provider as usual. Or, the patient could keep the US\$5,000 for some other purpose, which can vary. While preserving the risk-reducing feature of insurance, the split benefit makes part of the insurance benefit fungible, causing the patient to weigh the value of the treatment against other consumption alternatives. If patients decline the expensive, unproven treatment, the health insurer will save the balance (US\$45,000).

The payor can exercise the split benefit as a unilateral option whenever it is most likely to save money. It is consistent with current insurance contracts and regulations since it does not change coverage or the size of the benefit. It does not "ration" care, which the Medicare statute prohibits. Of course, the split benefit is not intended for inexpensive care where traditional cost sharing works. It is also contraindicated for high-value care, like vaccinations, and for care that is so frivolous that the insurer can exclude its coverage altogether. A vast swath remains between these poles.

The split benefit can be used alongside other cost-control mechanisms, including traditional cost sharing, exclusions of coverage, pre-authorizations, and fail-first policies. If the split is only a small fraction of the total cost of the procedure, the insurer can make several such payments for each instance of full-cost care that is deterred on the margin.

\section{Empirical questions about the split benefit concept}

This split benefit proposal raises important empirical questions. Would it actually save money? What size payment will be the "sweet spot" that saves the most money for the insurer at the least risk of wasteful payments on those who would not have consumed anyway? Which of the various ways that a split could be given - paid in advance, paid as a rebate of premiums for patients declining to consume, or deposited into a health savings account - would be most effective? Would beneficiaries view their insurers negatively if they paid a split benefit?

Ideally, these questions would be tested in real-world pilot experiments with sick patients and real money on the line. However, given the expense, logistics, and ethical limitations of such research, it is worthwhile to start with a laboratory study for this novel concept of health care reform. This article reports such an experiment.

\section{Experimental methods}

The Supplementary material provides detail, but in short: the concept was tested with subjects participating as "mock patients" in an online randomized experiment, using clinical vignettes, depicting decisions about whether to consume high-cost, low-value treatments. After collecting demographic information and asking about their source 
of insurance coverage (if any), participants were asked to imagine that they were ill, facing a health care decision.

Two clinical vignettes depicting off-label use of expensive procedures were used: heart stent and cancer drug. Hundreds of thousands of drug-eluting coronary stents are implanted each year for preventative purposes, with charges of US\$30,000-US\$100,000 each, even though they are not proven more effective than the cheaper and safer standard of care. ${ }^{1,19}$ Likewise, oncologists routinely use patented drugs, like Avastin ${ }^{\circledR}$ (Genentech Roche, San Francisco, CA, USA), with charges of over US\$80,000 for a course of treatment, for many conditions where they are unproven to provide any benefit. ${ }^{3}$ Halfway through the vignettes, the subjects were asked to write a few sentences about how they would respond to the scenario, just to increase engagement with the decision. Both vignettes were pilot tested and refined for clarity and content prior to use in the experiment described below.

Using a (two diseases $\times$ three types $\times$ two amounts) factorial design, these mock patients were randomized into either of the vignettes and into one of six split benefit conditions (manipulating type and amount of split) or control conditions (one for each disease). Each subject was randomized to a single condition. "Control" explained that the patient enjoyed full insurance, having surpassed annual cost sharing maximums. "Prepay" is a payment via bank check that the patient receives in advance of the health care decision, and simply keeps if they decline care. "Rebate" is an offer of payment after the decision is made, conditional on declining care, and is framed as a "rebate" of insurance premiums. "Limited" is also a prepayment, but paid into an account with fungibility limited to other health expenses, similar to a health savings account. Two levels of split (US\$5,000 and US\$15,000) were compared for each payment method.

Based on prospective power analyses (discussed in the Supplementary material), the study sought to recruit 1,800 participants to each review a single vignette in betweensubjects design. "Exempt" approval was received from the Human Subjects Protection Program at The University of Arizona (Tucson, AZ, USA), and a task was designed on Amazon Mechanical Turk (Amazon.com, Inc., Seattle, WA, USA), paying US\$0.75 per respondent. Amazon Mechanical Turk's screening feature was used to limit respondents to those within the US geographically. It was specified that respondents must be 18 years of age, and be able to read and write English.

After excluding respondents who failed to complete the task - those who did so in unreasonably long or short times - and duplicate records, there were 1,763 responses.
Qualtrics $^{\circledR}$ (Qualtrics, LLC, Provo, UT, USA) was used to randomly assign the respondents, yielding 425 in control, 449 in limited, 447 in prepay, and 447 in rebate conditions. There were 664 respondents for the US\$5,000 payment condition versus 679 in the US\$15,000 payment condition.

\section{Results and statistical analyses Respondents}

The study population was $52 \%$ male. In terms of education, $11 \%$ had graduated high school or had less education, while $40 \%$ had some college or an associate's degree and $49 \%$ had a bachelor's degree or more (including 12\% with advanced degrees). Ages ranged from 18-74 years, with a mean of 32 and a median of 28 . In terms of race and ethnicity, $83 \%$ of the study population reported being white, along with $6 \%$ reporting being black or African American, and 7\% Asian. A remaining 4\% reported being American Indian, Native Hawaiian, or other races. Politically, after flattening the sevenlevel scale, $21 \%$ identified as Republicans, $18 \%$ as Independents, and $61 \%$ as Democrats. The most common income range was US\$20,000-US\$29,999 (15\%) and two-thirds of the respondents had family incomes below US\$59,999. Table 1 shows the insurance status of respondents. The modal respondent $(33 \%)$ had private insurance through a current or former employer or union, with another $15 \%$ insured through the spouse's employer (total 48\%). The next most common response was uninsured (24\%). For the non-elderly population nationally, this compares to $56 \%$ getting insurance from employers and $18 \%$ being uninsured. ${ }^{20}$ Of those who had insurance, $31 \%$ reported that they were in a "high deductible health plan". One in seven (14\%) reported that they had a health savings account. None of these variables was

Table I Insurance status of responders

\begin{tabular}{ll}
\hline Insurance status & $\%$ \\
\hline Private insurance through my current or former employer or union & $33 \%$ \\
No, I am not currently covered by a health insurance plan & $24 \%$ \\
Private insurance through my spouse or partner's current or & $15 \%$ \\
former employer or union & \\
Private insurance bought directly from an insurance company or & $9 \%$ \\
HMO, or through a broker & \\
Other, or I don't know & $6 \%$ \\
A state's Medicaid program & $6 \%$ \\
Medicare & $4 \%$ \\
CHAMPUS, Tricare, CHAMPVA, Veterans Administration, or & $2 \%$ \\
other military health care & \\
Indian Health Service, a tribal health program, or urban Indian clinic & $0 \%$ \\
Total & $100 \%$ \\
\hline
\end{tabular}

Abbreviations: CHAMPVA, Civilian Health and Medical Program of the Veterans Administration; CHAMPUS, Civilian Health and Medical Program of the Uniformed Services; HMO, health maintenance organization. 
significantly associated with the primary dependent variable, intent to consume (insurance status $\chi^{2}[4]=3.85, P=0.43$; high deductibles $\chi^{2}[2]=0.19, P=0.66$; or health savings accounts $\left.\chi^{2}[2]=5.16, P=0.08\right)$.

\section{Efficacy in reducing consumption}

As the primary dependent variable, respondents were asked about the likelihood that they would consume the offered health care on a six-point Likert scale, which was converted to a binary outcome for analysis. The split benefit substantially reduced intent to consume. Across conditions, a large main effect appeared (Figure 1). In the control condition, $55 \%$ of respondents expressed an intention to consume, while across all split conditions, only $37 \%$ did so (odds ratio [OR]: 0.48, confidence interval [CI]: 0.38-0.60, $P<0.0001)$. The effect was especially strong in the cancer scenario, moving respondents from $69 \%$ in the control condition to $42 \%$ across all splits (OR: 0.32, CI: $0.23-0.45, P<0.0001$ ). An effect also appeared in the stent scenario, moving respondents from $42 \%$ consuming to $33 \%$ consuming (OR: 0.67 , CI: $0.49-0.92, P<0.01)$.

The proportion reporting an intent to consume, split by experimental condition, is shown in Figure 1. The variations as to type of payment did not differ in their efficacy in reducing intent to consume $(P=0.40)$. Only within the cancer scenario was there a significant difference between the US\$5,000 and the US\$15,000 split.

Finally, it was checked whether the flattening of the sixlevel scale for intent to consume to a binary variable had the consequence of discarding interesting information. As shown in Figures S1-S3, no interesting differences were observed.

\section{Regression models}

The logistic regression analyses, accounting for demographic factors and disease type, predict intent to consume - the primary dependent variable. As shown in Table S1, compared to the control condition (the reference of 1.0), the prepay condition reduces consumption very significantly (OR: 0.48 , CI: $0.36-0.64$ ), as does the limited condition (OR: 0.51 , CI: $0.38-0.69)$ and the rebate condition (OR: 0.43, CI: $0.32-0.57)$.

The various split benefit conditions also manipulated whether the insurer paid a US\$5,000 versus a US\$15,000 split. The levels of payment were indistinguishable in their effectiveness (OR: 0.94, CI: $0.75-1.17, P=0.59$ ). This finding is promising, because it suggests that insurers can use small splits that expose them to very little risk of losing money on net.

\section{Perceived fairness of insurer}

Respondents overwhelmingly thought that the insurer treated them very fairly, regardless of whether it paid a split benefit (Figure 2). Nonetheless, there were slightly different levels of agreement $(P=0.01)$, with higher fairness rating in the control $(95 \%)$ and prepay (95\%) conditions than the limited $(92 \%)$ and rebate $(90 \%)$ conditions. The amount of split made no detectable difference on this dependent variable $(P=0.16)$.

\section{Support for reform in Medicare}

Support for the idea of using the split benefit as a reform to Medicare was also examined. Overall, broad support was found, with $74 \%$ somewhat supporting, supporting, or strongly supporting the reform. As shown in Figure 3, the

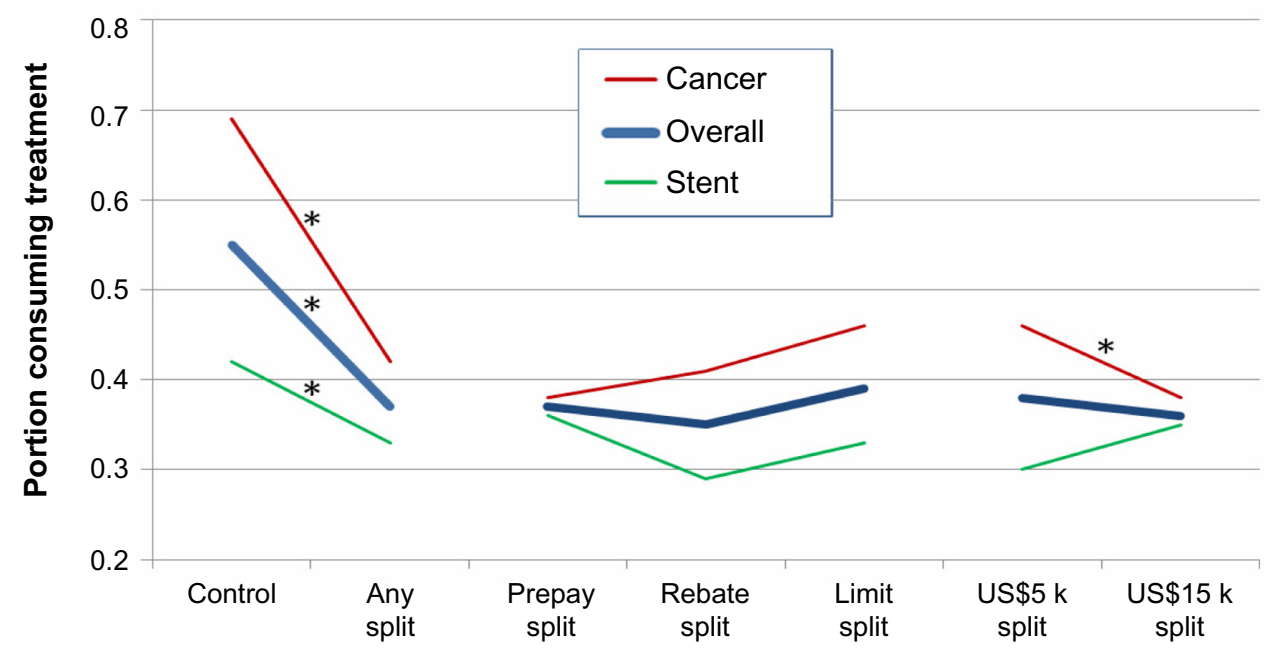

Figure I Intention to consume by experimental condition.

Notes: *Statistical significance $(P<0.05)$ in Yates-adjusted $\chi^{2}$ tests; $\mathrm{n}=I, 768$. 


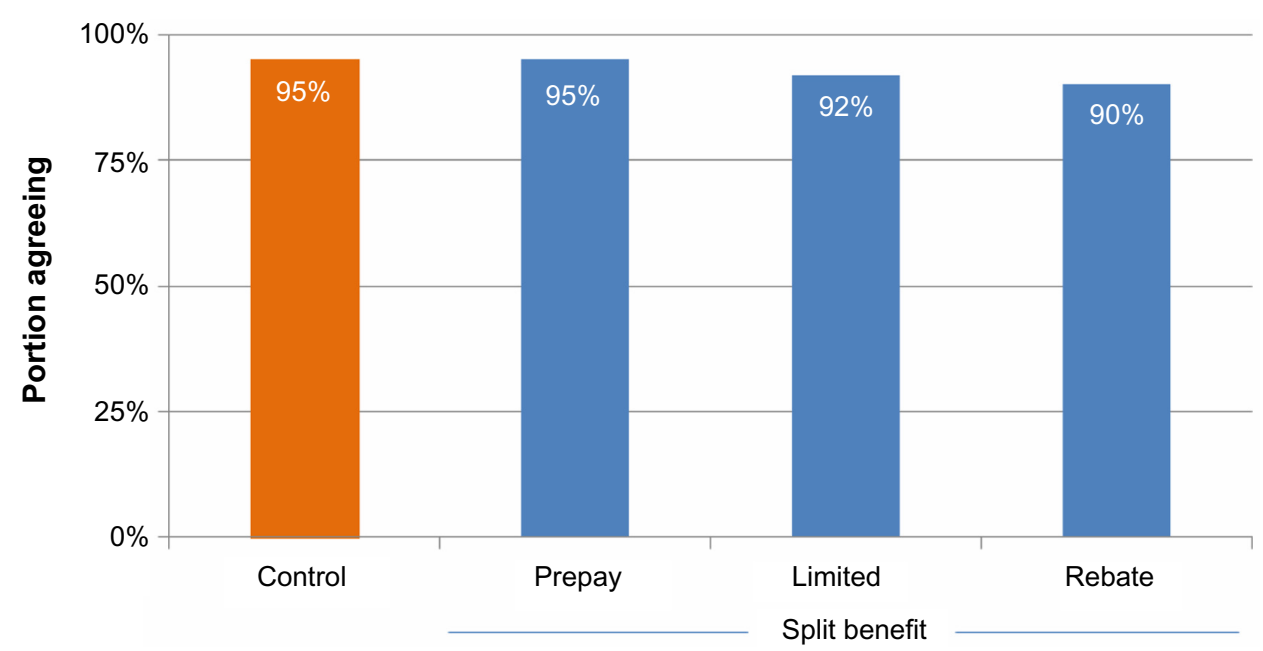

Figure 2 Perceptions that "insurer treated me fairly" by experimental condition.

Notes: Agreement includes those responding "strongly agree", "agree", or "somewhat agree" on a six-point Likert scale; $\mathrm{n}=1,768 ; \chi^{2}(3)=10.62 ; P=0.01$.

support did not depend on political affiliations, with Republicans $(n=366,70 \%)$, Independents $(n=321,77 \%)$, and Democrats $(\mathrm{n}=1,081,74 \%)$ showing similar favorability $(P=0.18)$. Lower income individuals were slightly more supportive of using the split benefit in Medicare (77\% versus $71 \%$, OR: 1.36, CI: $1.17-1.59, P<0.01)$.

For the Medicare reform questions, the types of split benefit in the primary "support reform" question were not specified. Respondents were subsequently asked, "What if the proposal included a feature that required that people who keep the split must deposit it in a health savings account, so that the money could only be used for future qualified health expenses? Would that make you more, or less, likely to support the proposal?" On a seven-point Likert scale,

Little variation by political affiliations or incomes

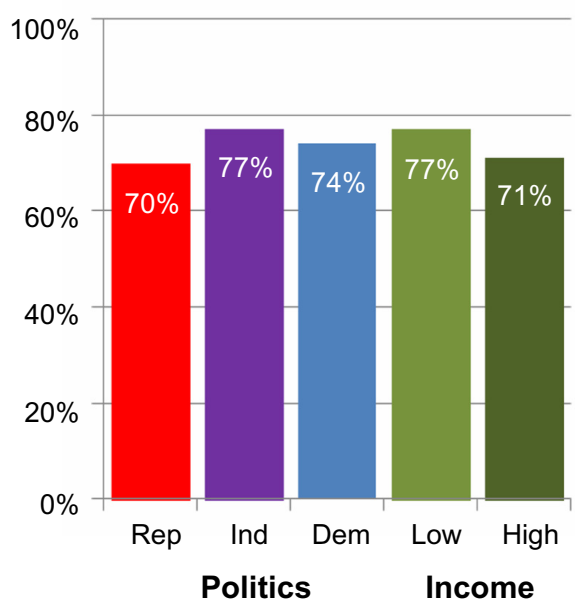

nearly two-thirds of the respondents (64\%) indicated that it would make them more likely (including somewhat and much more likely) to support the proposal if so limited. As shown above, such a limited payment may be equally effective at reducing low-value care.

\section{Discussion}

The foregoing results are promising, as they suggest that the split benefit could be useful as a way for public and private insurers to reduce consumption of the high-cost, low-value care that drives much of health spending. And, they can do so without reducing access or infringing on patient choice. Indeed, the data suggests that insurers have flexibility as to how they pay a split, in the amount and type.

What if the split could only be used for other health expenses?

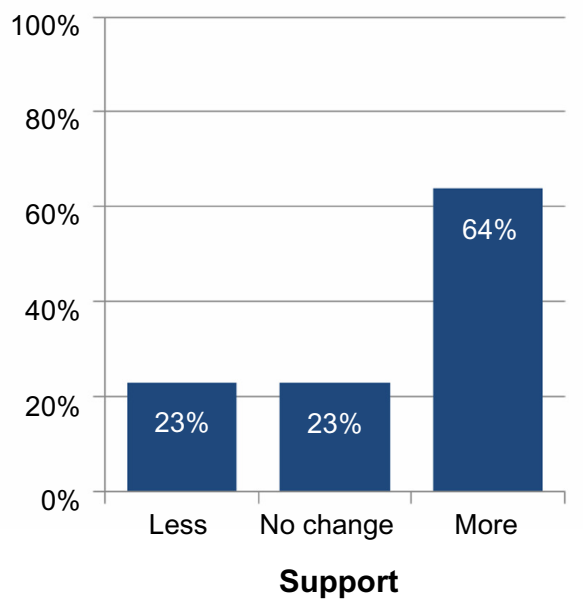

Figure 3 Support for split benefit as Medicare reform.

Notes: $n=I, 768$; politics: $P=0.18$; income: $P=0.01$.

Abbreviations: Rep, Republicans; Ind, Independents; Dem, Democrats. 
Those paying a split will be perceived fairly, since after all, the only effect of a split is to increase the patient's wealth and options.

This pilot study had a number of limitations. First, it used clinical vignettes in which patients were asked to imagine themselves in future situations, and to decide on that basis what they would do. The null results found with regard to type and amount of split may be due to the hypothetical nature of the task. Although respondents were asked to write about how they would feel in the situation, real patients may have a more profound emotional response, which would affect their treatment decisions. Second, the respondents were recruited from an online population that, although reasonably diverse, was not a demographically valid sample representing any particular insurance pool. Third, it used vignettes of two different medical domains where the split benefit might be utilized to reduce off-label consumption of expensive products. The reform might have larger, or smaller, effects in other contexts. Finally, the demographics of the study population varied substantially in comparison to the US population. The subject pool included fewer people at the very bottom of the education range (less than high school or General Educational Development [GED]), and fewer people at the high end of the age range (over 65 years). The study population is also somewhat less diverse in terms of race and ethnicity. The study population also skewed to the left politically, compared to the national population. As shown in the regressions, across all these demographic factors, in logistic regression it was found that only sex was associated with the primary dependent variable, intent to consume (OR: 1.32 CI: $1.09-1.61, P=0.004)$.

While the results are promising, several objections to the split benefit model come immediately to mind. Some have to do with "gaming" the system. Under such a reform, insurers would need to carefully regulate their strategies to minimize the risk of patients seeking split benefit payments for care that they otherwise would not have consumed anyway. Insurers could impose "fail first" policies, for example, that required patients and their providers to try standard of care treatments before even considering a treatment that might qualify for a split benefit payment. Patients choosing to forgo treatment in favor of the cash payment would not be eligible for full insurance coverage should they opt for the same intervention at some later stage. Since the split benefit would only be implemented for low-value interventions, individuals would still be eligible for insurance coverage for standard of care treatment for subsequent conditions or events. Even with these stipulations, there would likely be some degree of false demand stimulation. However, the split benefit reform may save money on net, if the payments are relatively small compared to the charge for the treatment. If an insurer can save US $\$ 45,000$ by paying US $\$ 5,000$, several instances of false demand can be tolerated, even while saving money on net.

The legal, clinical, and ethical implications of the split benefit model have been discussed in detail previously. ${ }^{18}$ Importantly, once a split benefit is paid, it functions in exactly the same way as a traditional co-insurance obligation. The advantage of a split benefit is that the strategy is not stymied by patient wealth. Unlike traditional cost sharing the burden does not undermine access to health care or drive anyone into bankruptcy or foreclosure.

One might recommend that the only interventions eligible for the split benefit model are those lacking clinical evidence of benefit. Unfortunately, a very large proportion of US health care spending has this character. For these interventions, where the clinical risk/benefit ratio is unclear, the payment of a split benefit does not make patients worse off than they would otherwise be. The decision to forgo treatment in these circumstances cannot be construed as choosing suboptimal care, because in this vacuum of evidence, it cannot be said that consumption is better than declining care.

The split benefit approach is most readily implemented by insurers in a fee for service payment model, and may help counteract some of the misaligned incentives that exist in those models. Under a capitation payment model, the provider instead bears the risk that patients will consume expensive health care. In principle, such providers could pay split benefits to patients as well. However, such an active role may undermine the relationship between patient and provider as it sharpens the conflicting interests.

The split benefit has been proposed not only as a way for private insurers to reduce the cost (and/or increase the actuarial value) of health insurance, but also as a reform for public insurers such as Medicare, seeking the same improvements. Reforms to such public programs are often highly contentious, and often polarizing between the political parties. Remarkably, the respondents in this study seemed generally supportive of the split benefit as a reform and did not polarize along party lines. Future public opinion survey research - with demographically valid samples - is necessary, but these results are promising.

Ultimately, the split benefit is attractive because, while cutting costs for insurers and insurance buyers, the mechanism keeps the consumption decision in the hands of the patients. For insurance buyers and political representatives, 
the split benefit will thus be a more attractive solution than further expansion of traditional cost sharing or outright rationing, which can stymie choice and reduce access. A powerful approach to increase the value of the health care dollar, where value is the quotient of outcomes/costs, is to decrease either utilization or spending on low-value interventions. The split benefit model can potentially accomplish both.

\section{Disclosure}

The authors report no conflicts of interest in this work.

\section{References}

1. Baicker K, Chandra A, Skinner JS. Saving money or just saving lives? Improving the productivity of US health care spending. Annu Rev Econom. 2012;4:33-56.

2. Congressional Budget Office. Technological Change and the Growth of Health Care Spending. Washington, DC: Congressional Budget Office; 2008. Available from: http://www.cbo.gov/ftpdocs/89xx/ doc8947/01-31-TechHealth.pdf. Accessed February 1, 2014.

3. Radley DC, Finkelstein SN, Stafford RS. Off-label prescribing among office-based physicians. Arch Intern Med. 2006;166(9):1021-1026.

4. Cassel CK, Guest JA. Choosing wisely: helping physicians and patients make smart decisions about their care. JAMA. 2012;307(17): 1801-1802.

5. Clinical evidence [homepage on the Internet]. London: BMJ Publishing Group; 2013. Available from: http://clinicalevidence.bmj.com. Accessed February 1, 2014.

6. Grady D, Redberg RF. Less is more: how less health care can result in better health. Arch Intern Med. 2010;170(9):749-750.

7. Garner S, Littlejohns P. Disinvestment from low value clinical interventions: NICEly done? BMJ. 2011;343:d4519.

8. Prasad V, Vandross A, Toomey C, et al. A decade of reversal: an analysis of 146 contradicted medical practices. Mayo Clin Proc. 2013;88(8): $790-798$.
9. Newhouse JP; Insurance Experiment Group. Free for all? Lessons From the RAND Health Insurance Experiment. Cambridge: Harvard University Press; 1993.

10. Swartz K. Cost-Sharing: Effects on Spending and Outcomes. Princeton, NJ: Robert Wood Johnson Foundation. Research; 2010. Available from: http://www.rwjf.org/content/dam/farm/reports/issue briefs/2010/rwjf402103/subassets/rwjf402103_1. Accessed April 27, 2014.

11. 2012 Employer Health Benefits Survey [webpage on the Internet]. Menlo Park, CA: Kaiser Family Foundation; 2012. Available from: http://kff.org/private-insurance/report/employer-health-benefits-2012annual-survey/. Accessed February 1, 2014.

12. Jost TS. Our broken health care system and how to fix it: an essay on health law and policy. Wake Forest Law Rev. 2006;41:537.

13. Nyman JA. The Theory of Demand for Health Insurance. Palo Alto: Stanford University Press; 2003.

14. Himmelstein DU, Thorne D, Warren EE, Woolhandler SS. Medical bankruptcy in the United States, 2007: results of a national study. Am J Med. 2009;122(8):741-746.

15. Schoen C, Collins SR, Kriss JL, Dory MM. How many are underinsured? Trends among US adults, 2003 and 2007. Health Aff (Millwood). 2008;17(4):w298-w309.

16. Kogan MD, Newacheck PW, Honberg L, Strickland B. Association between underinsurance and access to care among children with special health care needs in the United States. Pediatrics. 2005;116(5): 1162-1169.

17. Robertson CT, Egelhof R, Hoke M. Get sick, get out: the medical causes of home mortgage foreclosures. Health Matrix Clevel. 2008;18(65): 65-105.

18. Robertson CT. The split benefit: the painless way to put skin back in the health care game. Cornell Law Rev. 2013;98:921-964.

19. Win HK, Caldera AE, Maresh K, et al. Clinical outcomes and stent thrombosis following off-label use of drug-eluting stents. JAMA. 2007;297(18):2001-2009.

20. Blavin F, Holahan J, Kenney G, Chen V. A Decade of Coverage Losses: Implications for the Affordable Care Act. Menlo Park, CA: Robert Wood Johnson Foundation; 2012. Available from: http://www.urban org/UploadedPDF/412514-Implications-for-the-Affordable-Care-Act pdf. Accessed February 1, 2014.
Innovation and Entrepreneurship in Health

\section{Publish your work in this journal}

Innovation and Entrepreneurship in Health is an international, peer reviewed, open access journal publishing original research, reports, reviews and commentaries on innovation and entrepreneurship in health. Special focus will be given to the theory, process, and practice of innovation and entrepreneurship by individuals and organizations

\section{Dovepress}

within the health care context globally. The manuscript management system is completely online and includes a very quick and fair peer review system, which is all easy to use. Visit http://www.dovepress.com/ testimonials.php to read real quotes from published authors. 